Canadian

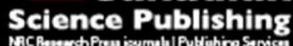

Applied Physiology, Nutrition, and Metabolism Physiologie appliquée, nutrition et métabolisme

\title{
Interactions between genetic polymorphisms of glucose metabolizing genes and smoking and alcohol consumption in the risk of type 2 diabetes mellitus
}

\begin{tabular}{|c|c|}
\hline Journal: & Applied Physiology, Nutrition, and Metabolism \\
\hline Manuscript ID & apnm-2017-0232.R1 \\
\hline Manuscript Type: & Article \\
\hline Date Submitted by the Author: & 28-Jul-2017 \\
\hline Complete List of Authors: & $\begin{array}{l}\text { Gao, Kaiping; Shenzhen University School of Medicine, Department of } \\
\text { Preventive Medicine } \\
\text { Ren, Yongcheng; College of Public Health, Zhengzhou University, } \\
\text { Department of Epidemiology } \\
\text { Wang, Jinjin; Preventive Medicine Research Evaluation Center, Henan } \\
\text { University of Traditional Chinese Medicine, Department of Traditional } \\
\text { Chinese Medicine Prevention } \\
\text { Liu, Zichen; Shenzhen University School of Medicine, Department of } \\
\text { Preventive Medicine } \\
\text { Li, Jianna; Shenzhen University School of Medicine, Department of } \\
\text { Preventive Medicine } \\
\text { Li, Linlin; College of Public Health, Zhengzhou University } \\
\text { Wang, Bingyuan; College of Public Health, Zhengzhou University } \\
\text { Li, Hong; Shenzhen University School of Medicine, Department of } \\
\text { Preventive Medicine } \\
\text { Wang, Yaxi; Shenzhen University School of Medicine, Department of } \\
\text { Preventive Medicine } \\
\text { Cao, Yunkai; Shenzhen University School of Medicine, Department of } \\
\text { Preventive Medicine } \\
\text { Ohno, Kinji; Nagoya Daigaku Igakubu Daigakuin Igakukei Kenkyuka } \\
\text { Fuzoku Shinkei Shikkan Shuyo Bunshi Igaku Kenkyu Center, Division of } \\
\text { Neurogenetics } \\
\text { Zhai, Rihong; Shenzhen University School of Medicine, Department of } \\
\text { Preventive Medicine } \\
\text { Liang, Zhen; The first Affiliated Hospital of Shenzhen University, } \\
\text { Department of Geriatric Medicine }\end{array}$ \\
\hline \multicolumn{2}{|l|}{$\begin{array}{r}\text { Is the invited manuscript for } \\
\text { consideration in a Special } \\
\text { Issue? : }\end{array}$} \\
\hline Keyword: & $\begin{array}{l}\text { glucose metabolizing genes, polymorphisms, gene-environment } \\
\text { interaction, type } 2 \text { diabetes mellitus }\end{array}$ \\
\hline
\end{tabular}


SCHOLARONE $^{m}$
Manuscripts

https://mc06.manuscriptcentral.com/apnm-pubs 
Interactions between genetic polymorphisms of glucose metabolizing genes and smoking and alcohol consumption in the risk of type 2 diabetes mellitus

Kaiping Gao ${ }^{1}$, Yongcheng Ren ${ }^{3}$, Jinjin Wang ${ }^{4}$, Zichen $\mathrm{Liu}^{1}$, Jianna $\mathrm{Li}^{1}$, Linlin $\mathrm{Li}^{3}$, Bingyuan Wang ${ }^{3}$, Hong $\mathrm{Li}^{1}$, Yaxi Wang ${ }^{1}$, Yunkai Cao ${ }^{1}$, Kinji Ohno ${ }^{5}$, Rihong Zhai ${ }^{1, *}$ and Zhen Liang ${ }^{2, *}$

Correspondce, Zhen Liang, $\mathrm{PhD}$, Department of Geriatric Medicine, The 1st Affiliated Hospital of Shenzhen University, 3002 West Sungang Road, Shenzhen, 518035, China; Tel: 0086-(0)755-83366388; Fax: 0086-(0)755-83356952; E-mail: sunylz@163.com. Rihong Zhai, Department of Preventive Medicine, Shenzhen University School of Medicine, Email: rzhai@szu.edu.cn.

${ }^{1}$ Department of Preventive Medicine, Shenzhen University School of Medicine, 3688 Nanhai Road, Shenzhen, 518060, China;

${ }^{2}$ Department of Geriatric Medicine, The 1st Affiliated Hospital of Shenzhen University, Shenzhen, 518035, China;

${ }^{3}$ Department of Epidemiology, College of Public Health, Zhengzhou University, Zhengzhou, 450001, China;

${ }^{4}$ Department of Traditional Chinese Medicine Prevention, Preventive Medicine Research Evaluation Center, Henan University of Traditional Chinese Medicine, Zhengzhou, 450001, China;

${ }^{5}$ Division of Neurogenetics, Center for Neurological Diseases and Cancer, University Graduate School of Medicine, Nagoya, 4668550, Japan 


\section{Abstract}

The impact of gene-environment interaction on diabetes remains largely unknown. We aimed to investigate whether interaction between glucose metabolizing genes and lifestyle factors are associated with type 2 diabetes mellitus (T2DM).

METHODS- Interactions between genotypes of 4 glucose metabolizing genes (MTNR1B, KCNQ1, KLF14, and GCKR) and lifestyle factors were estimated in 722 T2DM patients and 759 controls, using multiple logistic regression. RESULTS- No significant associations with T2DM were detected for the SNPs of MTNR1B, KLF14 and GCKR. However, rs151290 (KCNQ1) polymorphisms was found to be associated with risk of T2DM. Compared with AA, the ORs of AC or CC genotypes for developing T2DM were $1.545(P=0.0489)$ and 1,603 $(P=0.0383)$, respectively. In stratified analyses, the associations were stronger in smokers with $\mathrm{CC}$ than smokers with $\mathrm{AA}(\mathrm{OR}=3.668, P=0.013)$; drinkers with $\mathrm{AC}(\mathrm{OR}=5.518, P=0.036), \mathrm{CC}(\mathrm{OR}=8.691, P=0.0095)$, and $\mathrm{AC}+\mathrm{CC}(\mathrm{OR}=$ 6.764, $P=0.016$ ) than drinkers with AA. Compared with nondrinkers with AA, drinkers who carry AC and CC had 12.072-fold $(P=0.0007)$ and 8.147 -fold $(P=$ 0.0052) of higher risk of developing T2DM.

CONCLUSIONS- rs151290 (KCNQ1) polymorphisms are associated with increased risk of T2DM, alone and especially in interaction with smoking and alcohol.

\section{Keywords}

glucose metabolizing genes, polymorphisms, gene-environment interaction, type 2 diabetes mellitus, alcohol, smoking, $K C N Q 1$, Chinese population. 


\section{INTRODUCTION}

Type 2 diabetes mellitus (T2DM) is a leading cause of public health problem worldwide (Kelly et al. 2008), especially in developing nations. In recent years, a rapid increase in the prevalence of this disease has been observed in China, with up to 92.4 million people affected in 2010 (Yang et al. 2010).

T2DM is a complex disease, resulting from interactions between multiple genetic variants and environmental factors, including cigarette smoking and alcohol drinking (Mensink 2005). It has been well documented that smoking is an independent risk factor for insulin resistance and diabetes (Bergman et al. 2012), leading to 2.6-fold increased risk than that of nonsmokers Studies have also shown that moderate alcohol consumption reduces the risk (Joosten et al. 2010; Shi et al. 2013), Whereas heavy alcohol consumption is associated with increased risk of T2DM (Cullmann et al. 2012; Kao et al. 2001). Indeed, it has also been reported that alcohol can induce overall glucose intolerance by deregulating insulin-like growth factor I (IGF-I) and growth hormone (GH) (Kim et al. 2013).

To date, at least 16 diabetes-related genetic variants have been reported by Genome-wide association studies (GWAS) in various populations. These candidate single nucleotide polymorphism (SNPs) are mostly involved in the glucose metabolizing pathways. For example, variants at MTNR1B and $K C N Q 1$ genes were associated with reduced-cell function, and the locus at KLF14 was involved in reduced insulin sensitivity. 
Polymorphisms at $G C K R$ were implicated in fasting plasma glucose and triglyceride levels (Saxena et al. 2010; Voight et al. 2010; Yasuda et al. 2008). Among these diabetes-associated genetic variants, polymorphisms at rs10830963 of MTNR1B, rs151290 of KCNQ1, rs972283 of KLF14 and rs780094 of GCKR have been associated with diabetes in Asians including Chinese populations. Nevertheless, results from different studies were inconsistent (Hu et al. 2010; Ling et al. 2011; Liu et al. 2010; Gao et al. 2016), suggesting that other risk factors may influence the impact of genetic variants on the development of diabetes.

Over the last few years, several attempts have been made to explore how both genetic and environmental factors jointly contribute to the development of diabetes. It has been reported that the effects of polymorphisms in inflammatory cytokine genes, including IL-6 and TNF- $\alpha$, on the risk of T2DM are modified by nutrients such as low fat diet/virgin olive oil diet. For instance, a reduction in plasma saturated fatty acid (SFA) was associated with lower insulin resistance in subjects who were minor allele carriers of rs266729 in ADIPOQ and rs10920533 in ADIPOR1 (Nadeem et al. 2015). Interactions of genetic variants in the TLR3-TRIF-TRAF3-INF- $\beta$ signaling pathway genes and some particular environmental factors (LDL, BMI and HDL) may contribute to susceptibility to T2DM (Zhou et al. 2017). Genetic polymorphism in rs12104705 of glucagon gene interacts with smoking and physical activity to modify the risk of T2DM (Li et al. 2014). However, little is known about the effects of genetic variants in glucose metabolizing genes and 
environment factors on the development of T2DM.

We hypothesized that an interaction between the environment factors and susceptible genetic variants may play an important role in the risk of developing diabetes in Han Chinese. To test this hypothesis, we conducted a case-control study to examine the interactive effects of specific environmental factors (smoking and alcohol consumption) and polymorphisms in glucose metabolizing genes on the risk of T2DM in a Chinese population of 722 cases and 759 health controls.

\section{Materials and Methods}

\section{Study Subjects}

Patients and controls were obtained from the in Henan Province, China. Details on characteristics of cases and controls have been described previously (Gao et al. 2016). Patients were defined according to the criteria of American Diabetes Association (2006). Subjects were excluded from the study if they had the following disorders: type 1 diabetes mellitus with abnormal BMI ( $<18.5$ or $\geq 28.0)$ or glucose tolerance, pregnancy or handicapped, psychological conditions, use of obesity-related medicines, and malignant diseases. All participants gave written informed consent, and the study was reviewed and agreed by the institutional review boards of Shenzhen University Zhengzhou University (Protocol \#: 2014-2-1310-001 and 2014-3-1307-002).

The subjects were interviewed for the documentation of medical histories, demographic and anthropometric information, including age, body weight, 
height, waist circumference (WC), alcohol drinking and smoking status. Ethnic background was defined using self-reported information. Subjects who consumed $100 \mathrm{ml}$ liquor in 30 days were defined as alcohol drinkers (Crandall et al. 2009). Smoking status was classified as smoking and non-smoking. Subjects that were currently smoked and/or had smoked a total of $\geq 100$ cigarettes in their life were defined as smokers (Zhai et al. 2014). Subjects with FBG level of $3.6 \sim 6.1 \mathrm{mmol} / \mathrm{L}$ were considered as health controls.

\section{Selection criteria for candidate SNPs}

Genetic variants that met one of the following criteria were considered as candidate diabetes-related SNPs : (1) Functional SNPs that have been linked to fasting glucose, insulin release and sensitivity;

Diabetes-related polymorphisms reported by previous GWAS studies; (3) Minor allele frequency (MAF) $\geq 0.30$ in Chinese (http://www.hapmap.org); (4) Potentially functional loci (e.g. coding, in UTR, promoter and splicing site). Based on these criteria, 4 SNPs in 4 glucose metabolism genes (rs10830963, rs151290, rs972283 and rs780094 at $M T N R 1 B, K C N Q 1, K L F 14$ and $G C K R$ genes, respectively) were included in the present study (Supplementary Table S1 ${ }^{1}$ ).

\section{Genotyping Assays}

Peripheral venous blood samples were collected from all study subjects and the genome DNA was extracted from peripheral leukocytes by the

\footnotetext{
${ }^{1}$ Supplementary data are available with the article through the journal Web site at http://nrcresearchpress.com/doi/suppl/10.1139/apnm-2017-0232
} 
conventional proteinase-phenol-chloroform extraction method. Genotypes were determined by the Prism 7000 system (Applied Biosystems Inc.). A $20 \%$ of the samples were randomly included in PCR plates for quality control. $100 \%$ of cases and $100 \%$ of controls were genotyped successfully (Supplementary Figure $\mathrm{S}^{1}$ ). The probe sequences used for the present study are listed in Supplementary Table S2 ${ }^{1}$. The concordance rate of 5\% repeated samples was $100 \%$ (primers shown in Supplementary Table S3 ${ }^{1}$ ).

\section{Statistical Analysis}

Sample size and statistical power were estimated using the PGA package (http://dceg.cancer.gov/bb/tools/pga). Differences in variables between subgroups were determined by Wilcoxon rank sum test. Hardy-Weinberg equilibrium was assessed by Fisher exact test (Salanti et al. 2005). Between-group differences in genetic variables were assessed by $\chi^{2}$ analysis. Logistic regression was performed to determine variables associated with $\mathrm{T} 2 \mathrm{DM}$ and to estimate confounding factors possibly disturbing the relations. Adjusting for gender, age, BMI, waist circumference, environmental factors (smoking, alcohol consumption), and biochemical variables. All data were analyzed by the SAS for Windows version 9.1.3. Tests were two-sided and a $\mathrm{P}$ value of $<0.05$ was considered significant.

\section{Results}

\section{Population Characteristics}

A total of 722 patients with T2DM and 759 healthy controls were 
included in the present study. Basic demographic and clinical information for cases and controls are summarized in Table 1 and Supplementary Table S4 ${ }^{1}$. Levels of FBG, BMI and waist circumference, and rate of drinking were statistically different between cases and controls. The mean age in patients was significantly older than that in controls.

\section{Associations between genetic variants and T2DM risk}

All 4 SNPs studied were in Hardy-Weinberg equilibrium in controls $(P>0.1)$. Genotype frequencies of KCNQ1 (rs151290) among patients differed significantly from those among controls $(\mathrm{P}=0.0370)$. Nevertheless, no differences of genotype frequencies were found between patients and controls for MTNR1B (rs10830963), KLF14 (rs972283) and GCKR (rs780094) (Supplementary Table $\mathrm{S}^{1}{ }^{1}$ ).

Compared with subjects with the AA genotype, individuals carried the AC, $\mathrm{CC}$, and the $\mathrm{AC}+\mathrm{CC}$ genotype of the KCNQ1 (rs151290) had adjusted ORs of $1.482(\mathrm{P}=0.0208), 1.544(\mathrm{P}=0.0126)$, and $1.509(\mathrm{P}=0.0114)$ for developing T2DM, respectively. No genetic variants of other three polymorphisms found to be associated with the risk of T2DM (all P > $0.05)$ (Table 2).

\section{Stratified analysis of association between genetic variants and T2DM risk}

When analysis was restricted in non-drinkers, no significant association was observed for any genotypes of the 4 polymorphisms. In drinkers, however, individuals with the $\mathrm{AC}, \mathrm{CC}$, and the combined $\mathrm{AC}+\mathrm{CC}$ genotypes at the rs151290 had 5.518- $(\mathrm{P}=0.036), 8.691-(\mathrm{P}=0.0095)$, 
and 6.764- $(\mathrm{P}=0.016)$ fold increased risk of developing $\mathrm{T} 2 \mathrm{DM}$ than drinkers who carried the AA genotype, respectively. In smokers, a trend of higher risk of developing T2DM was also found for subjects with the AC, $\mathrm{CC}$, and $\mathrm{AC}+\mathrm{CC}$ genotypes of rs 151290 , but only the association between CC genotype with smoking and diabetes reached statistical significance. $(\mathrm{OR}=3.668, \mathrm{P}=0.013)$. No interactions between smoking and alcohol consumption and any genotypes of the other three SNPs (rs10830963, rs972283 and rs780094) were detected to be associated with the development of T2DM in this Han population (Table 3).

We further examined whether drinking status had an interactive effect with KCNQ1 (rs151290) genotypes on T2DM risk. Compared with nondrinkers carried the AA genotype, drinkers with the $\mathrm{AC}$ and $\mathrm{CC}$ genotypes had more than 12-fold $(\mathrm{P}=0.0007)$ and 8 -fold $(\mathrm{P}=0.0052)$ increased risk of developing $\mathrm{T} 2 \mathrm{DM}$, suggesting that interaction between the rs151290 polymorphisms and drinking was associated with T2DM development (Figure 1).

\section{Discussion}

In the present study, we observed that functional SNPs of KCNQ1 (rs151290), particularly genotypes with the C allele, are associated with susceptibility to T2DM in a Han Chinese. More interestingly, we found that genetic variants of rs 151290 can modify the risk of T2DM not only by itself but also by interacting with smoking and drinking in gene-environment interaction fashion. 
Our findings are consistent with prior knowledge that KCNQ1 is implicated in T2DM pathogenesis. The KCNQ1 (potassium voltage-gated channel KQT-like subfamily, member 1) gene contains 19 exons and spans more than $400 \mathrm{~kb}$ on chromosome 11p15.5 (Neyroud et al. 1999), encoding the subunit of a voltage-gated $\mathrm{K}+$ channel (KvLQT1) that plays a critical role in the repolarization of the cardiac action potential as well as water and salt transport in epithelial tissues (Neyroud et al. 1997; Wang et al. 1996). Mutations in this gene can lead to the long QT syndrome and deafness (Demolombe et al. 2001; Splawski et al. 2000; Ullrich et al. 2005), and obstruction of the KCNQ1 inhibitors 293B channel would enhance insulin secretion in the presence of tolbutamide (Ullrich et al. 2005), suggesting that KCNQ1 may take part in modulation of insulin production.

We observed that KCNQ1 may contribute to T2DM development through interactions with drinking and smoking. These observations were biologically plausible. Smoking and drinking (especially heavy alcohol consumption) are known risk factors for diabetes (Cullmann et al. 2012; Ko et al. 2011; Lajous et al. 2013; Pietraszek et al. 2010; Willi et al. 2007; Zhang et al. 2011). Both smoking and alcohol can induce an increased risk of cardiovascular disease, which is an established independent risk for insulin resistance and T2DM (Briasoulis et al. 2012; Cosselman et al. 2015; Mostofsky et al. 2016; Pan et al. 2015). Furthermore, it has been reported that cigarette smoking (Briasoulis et al. 2012; Cosselman et al. 2015; Mostofsky et al. 2016; Pan et al. 2015) or alcohol (Barcia et al. 
2015) may result in various systemic effects including oxidative stress, systematic inflammation, and endothelial dysfunction, all of which have been linked to insulin resistance (Akter et al. 2015; Mostofsky et al. 2016). In addition, nicotine in cigarette has a direct toxic effect on beta cell function (Chowdhury et al. 2002); similarly, chronic ethanol consumption may induce pancreatic $\beta$-cell apoptosis and dysfunction (Kim et al. 2015). Specifically, it has been found that cigarette smoking and alcohol consumption are related to glycemic control and insulin resistance (Cosselman et al. 2015; Ohkuma et al. 2015; Steiner et al. 2015).

In this study, gene-environment interactions were observed between KCNQ1 polymorphisms and alcohol drinking and smoking. The mechanisms underlying these interactions are still unknown. However, it has been suggested that genes encoding the KCNQ1 (kv7.1) channels are related to alcohol consumption, preference and acceptance in rodents (McGuier et al. 2016). Activation of the Kv7 potassium channel using retigabine may decrease the reactivity of mesolimbic dopaminergic neurons that are implicated in mediating the reinforcing effects of ethanol (Knapp et al. 2014), The expression of the KCNQ genes is associated with drinking and administration of retigabine reduces consumption of alcohol in mice, suggesting that Kv7 channel could be potential pharmacogenetics targets to treat individuals with alcohol addiction (Rinker et al. 2017). Moreover, tobacco smoking has been found to be associated with polymorphisms in the KCNQ1 gene, which is implicated in hypomethylation of cg26963277 (KCNQ1), a biological process relating 
to lower fasting insulin levels (Ligthart et al. 2016).

This study has several limitations. First, we focused on a few candidate polymorphisms, which allowed us to compare our study with studies where the biological function of these SNPs have been found, but therefore would not allow us to evaluate the comprehensive effect of the entire genes. Our study does, however, provide a guide for future studies that will replicate these findings, either through in vitro or in vivo studies. Second, smoking and drinking statuses were collected on self-reported basis and were not validated by confirmatory studies such as metabolites measurements. Third, no information regarding the reasons for not drinking or smoking was collected. Hence, it is likely that the nonsmoker and non-drinker groups may include an unknown percentage of subjects who stopped drinking or smoking for a variety of health reasons, but the effects of such groups on the results are extremely difficult to define. Fourth, dietary patterns and other environmental exposures were not able to be adjusted in the analyses because of missing or uncollected data. Given the strong interaction effects detected in this study, these potential confounders would probably have minor influence on the results.

In summary, the results of this study show that KCNQ1 (rs151290) polymorphism exerts its effect on T2DM susceptibility through an interaction with lifestyle factors. Specifically, genotypes with the $\mathrm{C}$ allele are associated with the greatest risk of T2DM among alcohol drinkers. Our findings suggest that gene-environment interactions between smoking and alcohol consumption and genetic polymorphisms in glucose 
metabolizing pathway genes may play important roles in the pathogenesis of T2DM, raising the prospect of research for personalized strategies in T2DM prevention.

\section{Acknowledgments}

The Natural Science Foundation of Guangdong Province (nos. S2013010016791), the Medical Science and Technology Research Foundation of Guangdong Province (nos. A2016213), the Science and Technology Development Foundation of Shenzhen (nos. JCYJ20130326110246234, nos. JCYJ20140416180032316 and nos. JCYJ20150324141711609). We would like to thank all patients and their families for collaboration with this study.

\section{Conflict of Interest}

None of the authors has any conflict of interest to declare.

\section{References:}

American Diabetes Association. 2006. Diagnosis and classification of diabetes mellitus. Diabetes Care, 29 Suppl 1: S43-S48.

Akter, S., Okazaki, H., Kuwahara, K., Miyamoto, T., Murakami, T., Shimizu, C., et al. 2015. Smoking, Smoking Cessation, and the Risk of Type 2 Diabetes among Japanese Adults: Japan Epidemiology Collaboration on Occupational Health Study. PLoS One, 10(7): e132166. doi: 10.1038/hr.2016.51. Epub 2016 Jun 2. PMID: 27250568.

Barcia, J.M., Flores-Bellver, M., Muriach, M., Sancho-Pelluz, J., Lopez-Malo, D., Urdaneta, A.C., et al. 2015. Matching Diabetes and Alcoholism: Oxidative Stress, Inflammation, and Neurogenesis Are Commonly Involved. Mediators Inflamm. 2015: 624287. doi: 10.1155/2015/624287. Epub 2015 May 7. PMID: 26063976.

Bergman, B.C., Perreault, L., Hunerdosse, D., Kerege, A., Playdon, M., Samek, A.M., et al. 2012. Novel and reversible mechanisms of smoking-induced insulin resistance in humans. Diabetes, 61(12): 3156-3166. doi: 10.2337/db12-0418. Epub 2012 Sep 10. PMID: 22966072.

Briasoulis, A., Agarwal, V., and Messerli, F.H. 2012. Alcohol consumption and the risk of hypertension in men and women: a systematic review and meta-analysis. J. Clin. Hypertens. 14(11): 792-798. doi: 10.1111/jch.12008. Epub 2012 Sep 25. PMID: 23126352.

Chowdhury, P., MacLeod, S., Udupa, K.B., and Rayford, P.L. 2002. Pathophysiological effects of 
nicotine on the pancreas: an update. Exp. Biol. Med. 227(7): 445-454. PMID: 12094008.

Cosselman, K.E., Navas-Acien, A., and Kaufman, J.D. 2015. Environmental factors in cardiovascular disease. Nat. Rev. Cardiol. 12(11): 627-642. doi: 10.1038/nrcardio.2015.152. Epub 2015 Oct 13. PMID: 26461967.

Crandall, J.P., Polsky, S., Howard, A.A., Perreault, L., Bray, G.A., Barrett-Connor, E., et al. 2009. Alcohol consumption and diabetes risk in the Diabetes Prevention Program. Am. J. Clin. Nutr. 90(3): 595-601. doi: 10.3945/ajcn.2008.27382. Epub 2009 Jul 29. PMID: 19640960.

Cullmann, M., Hilding, A., and Ostenson, C.G. 2012. Alcohol consumption and risk of pre-diabetes and type 2 diabetes development in a Swedish population. Diabet. Med. 29(4): 441-452. doi: 10.1111/j.1464-5491.2011.03450.x. PMID: 21916972.

Demolombe, S., Franco, D., de Boer, P., Kuperschmidt, S., Roden, D., Pereon, Y., et al. 2001. Differential expression of KvLQT1 and its regulator IsK in mouse epithelia. Am. J. Physiol. Cell Physiol. 280(2): C359-C372. PMID: 11208532.

Gao, K., Wang, J., Li, L., Zhai, Y., Ren, Y., You, H., et al. 2016. Polymorphisms in Four Genes (KCNQ1 rs151290, KLF14 rs972283, GCKR rs780094 and MTNR1B rs10830963) and Their Correlation with Type 2 Diabetes Mellitus in Han Chinese in Henan Province, China. Int J Environ. Res. Public Health, 13(3). doi: 10.3390/ijerph13030260. PMID: 26927145.

Hu, C., Zhang, R., Wang, C., Yu, W., Lu, J., Ma, X., et al. 2010. Effects of GCK, GCKR, G6PC2 and MTNR1B variants on glucose metabolism and insulin secretion. PLoS One, 5(7): e11761. doi: 10.1371/journal.pone.0011761. PMID: 20668700.

Joosten, M.M., Grobbee, D.E., van der A, D.L., Verschuren, W.M., Hendriks, H.F., and Beulens, J.W. 2010. Combined effect of alcohol consumption and lifestyle behaviors on risk of type 2 diabetes. Am. J. Clin. Nutr. 91(6): 1777-1783. doi: 10.3945/ajcn.2010.29170. Epub 2010 Apr 21. PMID: 20410096

Kao, W.H., Puddey, I.B., Boland, L.L., Watson, R.L., and Brancati, F.L. 2001. Alcohol consumption and the risk of type 2 diabetes mellitus: atherosclerosis risk in communities study. Am. J. Epidemiol. 154(8): 748-757. PMID: 11590088.

Kelly, T., Yang, W., Chen, C.S., Reynolds, K., and He, J. 2008. Global burden of obesity in 2005 and projections to 2030. Int. J. Obes. 32(9): 1431-1437. doi: 10.1038/ijo.2008.102. Epub 2008 Jul 8. PMID: 18607383.

Kim, J.Y., Lee, D.Y., Lee, Y.J., Park, K.J., Kim, K.H., Kim, J.W., et al. 2015. Chronic alcohol consumption potentiates the development of diabetes through pancreatic beta-cell dysfunction. World J. Biol. Chem. 6(1): 1-15. doi: 10.4331/wjbc.v6.i1.1. PMID: 25717351.

Kim, S.J., Ju, A., Lim, S.G., and Kim, D.J. 2013. Chronic alcohol consumption, type 2 diabetes mellitus, insulin-like growth factor-I (IGF-I), and growth hormone (GH) in ethanol-treated diabetic rats. Life Sci. 93(21): 778-782. doi: 10.1016/j.lfs.2013.09.018. Epub 2013 Sep 29. PMID: 24084046. doi: 10.1016/j.lfs.2013.09.018. Epub 2013 Sep 29. PMID: 24084046.

Knapp, C.M., O'Malley, M., Datta, S., and Ciraulo, D.A. 2014. The Kv7 potassium channel activator retigabine decreases alcohol consumption in rats. Am. J. Drug Alcohol. Abuse, 40(3): 244-250. doi: 10.3109/00952990.2014.892951. Epub 2014 Apr 15. PMID: 24735395.

Ko, K.P., Min, H., Ahn, Y., Park, S.J., Kim, C.S., Park, J.K., et al. 2011. A prospective study investigating the association between environmental tobacco smoke exposure and the incidence of type 2 diabetes in never smokers. Ann. Epidemiol. 21(1): 42-47. doi: 
10.1016/j.annepidem.2010.10.006. PMID: 21130368.

Lajous, M., Tondeur, L., Fagherazzi, G., de Lauzon-Guillain, B., Boutron-Ruaualt, M.C., and Clavel-Chapelon, F. 2013. Childhood and adult secondhand smoke and type 2 diabetes in women. Diabetes Care, 36(9): 2720-2725. doi: 10.2337/dc12-2173. Epub 2013 Jun 11. PMID: 23757428 .

Li, L., Gao, K., Zhao, J., Feng, T., Yin, L., Wang, J., et al. 2014. Glucagon gene polymorphism modifies the effects of smoking and physical activity on risk of type 2 diabetes mellitus in Han Chinese. Gene, 534(2): 352-355. doi: 10.1016/j.gene.2013.09.121. Epub 2013 Nov 1. PMID: 24185078.

Ligthart, S., Steenaard, R.V., Peters, M.J., van Meurs, J.B., Sijbrands, E.J., Uitterlinden, A.G., et al. 2016. Tobacco smoking is associated with DNA methylation of diabetes susceptibility genes. Diabetologia, 59(5): 998-1006. doi: 10.1007/s00125-016-3872-0. Epub 2016 Jan 29. PMID: 26825526.

Ling, Y., Li, X., Gu, Q., Chen, H., Lu, D., and Gao, X. 2011. Associations of common polymorphisms in GCKR with type 2 diabetes and related traits in a Han Chinese population: a case-control study. BMC Med. Genet. 12: 66. doi: 10.1186/1471-2350-12-66. PMID: 21569451.

Liu, C., Wu, Y., Li, H., Qi, Q., Langenberg, C., Loos, R.J., et al. 2010. MTNR1B rs10830963 is associated with fasting plasma glucose, $\mathrm{HbA1C}$ and impaired beta-cell function in Chinese Hans from Shanghai. BMC Med. Genet. 11: 59. doi: 10.1186/1471-2350-11-59. PMID: 20398260.

McGuier, N.S., Griffin, W.R., Gass, J.T., Padula, A.E., Chesler, E.J., and Mulholland, P.J. 2016. Kv7 channels in the nucleus accumbens are altered by chronic drinking and are targets for reducing alcohol consumption. Addict. Biol. 21(6): 1097-1112. doi: 10.1111/adb.12279. Epub 2015 Jun 23. PMID: 26104325.

Mensink, M. 2005. Lifestyle intervention, glucose tolerance, and risk of developing type 2 diabetes mellitus. Metab. Syndr. Relat. Disord. 3(1): 26-34. doi: 10.1089/met.2005.3.26. PMID: 18370707.

Mostofsky, E., Chahal, H.S., Mukamal, K.J., Rimm, E.B., and Mittleman, M.A. 2016. Alcohol and Immediate Risk of Cardiovascular Events: A Systematic Review and Dose-Response Meta-Analysis. Circulation, 133(10): 979-987. doi: 10.1161/CIRCULATIONAHA.115.019743. PMID: 26936862.

Nadeem, A., Mumtaz, S., Naveed, A.K., Aslam, M., Siddiqui, A., Lodhi, G.M., et al. 2015. Gene-gene, gene-environment, gene-nutrient interactions and single nucleotide polymorphisms of inflammatory cytokines. World J. Diabetes, 6(4): 642-647. doi: 10.4239/wjd.v6.i4.642. PMID: 25987962.

Neyroud, N., Tesson, F., Denjoy, I., Leibovici, M., Donger, C., Barhanin, J., et al. 1997. A novel mutation in the potassium channel gene KVLQT1 causes the Jervell and Lange-Nielsen cardioauditory syndrome. Nat. Genet. 15(2): 186-189. PMID: 9020846.

Neyroud, N., Richard, P., Vignier, N., Donger, C., Denjoy, I., Demay, L., et al. 1999. Genomic organization of the KCNQ1 K+ channel gene and identification of C-terminal mutations in the long-QT syndrome. Circ. Res. 84(3): 290-297. PMID: 10024302.

Ohkuma, T., Iwase, M., Fujii, H., Kaizu, S., Ide, H., Jodai, T., et al. 2015. Dose- and 
time-dependent association of smoking and its cessation with glycemic control and insulin resistance in male patients with type 2 diabetes mellitus: the Fukuoka Diabetes Registry. PLoS One, 10(3): e122023. doi: 10.1371/journal.pone.0122023. eCollection 2015. PMID: 25822499.

Pan, A., Wang, Y., Talaei, M., and Hu, F.B. 2015. Relation of Smoking With Total Mortality and Cardiovascular Events Among Patients With Diabetes Mellitus: A Meta-Analysis and Systematic Review. Circulation, 132(19): 1795-1804. doi: 10.1161/CIRCULATIONAHA.115.017926. Epub 2015 Aug 26. PMID: 26311724.

Pietraszek, A., Gregersen, S., and Hermansen, K. 2010. Alcohol and type 2 diabetes. A review. Nutr. Metab. Cardiovasc. Dis. 20(5): 366-375. PMID: 20556883.

Rinker, J.A., Fulmer, D.B., Trantham-Davidson, H., Smith, M.L., Williams, R.W., Lopez, M.F., et al. 2017. Differential potassium channel gene regulation in BXD mice reveals novel targets for pharmacogenetic therapies to reduce heavy alcohol drinking. Alcohol. 58: 33-45. doi: 10.1016/j.alcohol.2016.05.007. Epub 2016 Jun 27. PMID: 27432260.

Salanti, G., Amountza, G., Ntzani, E.E., and Ioannidis, J.P. 2005. Hardy-Weinberg equilibrium in genetic association studies: an empirical evaluation of reporting, deviations, and power. Eur $\mathrm{J}$ Hum. Genet. 13(7): 840-848. PMID: 15827565.

Saxena, R., Hivert, M.F., Langenberg, C., Tanaka, T., Pankow, J.S., Vollenweider, P., et al. 2010. Genetic variation in GIPR influences the glucose and insulin responses to an oral glucose challenge. Nat. Genet. 42(2): 142-148. doi: 10.1038/ng.521. Epub 2010 Jan 17. PMID: 20081857.

Shi, L., Shu, X.O., Li, H., Cai, H., Liu, Q., Zheng, W., et al. 2013. Physical activity, smoking, and alcohol consumption in association with incidence of type 2 diabetes among middle-aged and elderly Chinese men. PLoS One, 8(11): e77919. doi: 10.1371/journal.pone.0077919. eCollection 2013. PMID: 24223743.

Splawski, I., Shen, J., Timothy, K.W., Lehmann, M.H., Priori, S., Robinson, J.L., et al. 2000. Spectrum of mutations in long-QT syndrome genes. KVLQT1, HERG, SCN5A, KCNE1, and KCNE2. Circulation, 102(10): 1178-1185. PMID: 10973849.

Steiner, J.L., Crowell, K.T., and Lang, C.H. 2015. Impact of Alcohol on Glycemic Control and Insulin Action. Biomolecules, 5(4): 2223-2246. doi: 10.3390/biom5042223. PMID: 26426068.

Ullrich, S., Su, J., Ranta, F., Wittekindt, O.H., Ris, F., Rosler, M., et al. 2005. Effects of I(Ks) channel inhibitors in insulin-secreting INS-1 cells. Pflugers. Arch. 451(3): 428-436. PMID: 16133261.

Voight, B.F., Scott, L.J., Steinthorsdottir, V., Morris, A.P., Dina, C., Welch, R.P., et al. 2010. Twelve type 2 diabetes susceptibility loci identified through large-scale association analysis. Nat. Genet. 42(7): 579-589. doi: 10.1038/ng.609. PMID: 20581827.

Wang, Q., Curran, M.E., Splawski, I., Burn, T.C., Millholland, J.M., VanRaay, T.J., et al. 1996. Positional cloning of a novel potassium channel gene: KVLQT1 mutations cause cardiac arrhythmias. Nat. Genet. 12(1): 17-23. PMID: 8528244.

Willi, C., Bodenmann, P., Ghali, W.A., Faris, P.D., and Cornuz, J. 2007. Active smoking and the risk of type 2 diabetes: a systematic review and meta-analysis. JAMA, 298(22): 2654-2664. PMID: 18073361.

Yang, W., Lu, J., Weng, J., Jia, W., Ji, L., Xiao, J., et al. 2010. Prevalence of diabetes among men and women in China. N. Engl. J. Med. 362(12): 1090-1101. doi: 10.1056/NEJMoa0908292. 
PMID: 20335585.

Yasuda, K., Miyake, K., Horikawa, Y., Hara, K., Osawa, H., Furuta, H., et al. 2008. Variants in KCNQ1 are associated with susceptibility to type 2 diabetes mellitus. Nat. Genet. 40(9): 1092-1097. doi: 10.1038/ng.207. PMID: 18711367.

Zhai, R., Yu, X., Wei, Y., Su, L., and Christiani, D.C. 2014. Smoking and smoking cessation in relation to the development of co-existing non-small cell lung cancer with chronic obstructive pulmonary disease. Int. J. Cancer, 134(4): 961-970. doi: 10.1002/ijc.28414. Epub 2013 Aug 29. PMID: 23921845.

Zhang, L., Curhan, G.C., Hu, F.B., Rimm, E.B., and Forman, J.P. 2011. Association between passive and active smoking and incident type 2 diabetes in women. Diabetes Care, 34(4): 892-897. doi: 10.2337/dc10-2087. Epub 2011 Feb 25. PMID: 21355099.

Zhou, Z., Zeng, C., Nie, L., Huang, S., Guo, C., Xiao, D., et al. 2017. The effects of TLR3, TRIF and TRAF3 SNPs and interactions with environmental factors on type 2 diabetes mellitus and vascular complications in a Han Chinese population. Gene, 626: 41-47. doi: 10.1016/j.gene.2017.05.011. Epub 2017 May 4. PMID: 28479387. 
Table 1

Demographic characteristics of T2DM patients and controls

\begin{tabular}{|c|c|c|c|c|c|}
\hline \multicolumn{2}{|c|}{ Characteristics } & $\begin{array}{l}\text { T2DM patients } \\
\qquad(\mathrm{n}=722)\end{array}$ & $\begin{array}{l}\text { Controls } \\
(\mathrm{n}=759)\end{array}$ & $Z / \chi^{2}$ & $P$ \\
\hline \multirow{2}{*}{ Sex* } & Male & $417(57.8)$ & 317 (41.8) & \multirow{2}{*}{37.24} & \multirow{2}{*}{$<0.001$} \\
\hline & Female & $305(42.2)$ & $442(58.2)$ & & \\
\hline \multicolumn{2}{|c|}{ Age (years) ${ }^{\#}$} & $53(44-61)$ & $48(41-57)$ & 6.412 & $<0.001$ \\
\hline \multicolumn{2}{|l|}{$\mathrm{FBG}^{\#}$} & $7.0(5.7-9.2)$ & $5.2(4.9-5.5)$ & 24.35 & $<0.001$ \\
\hline \multicolumn{2}{|c|}{ BMI $\left(\mathrm{kg} / \mathrm{m}^{2}\right)^{\#}$} & $28.6(25.4-32.1)$ & $23.5(21.4-25.9)$ & 20.669 & $<0.001$ \\
\hline \multicolumn{2}{|c|}{$\mathrm{WC}(\mathrm{cm})^{\#}$} & $94.5(88-106)$ & $81.3(75-87)$ & 21.23 & $<0.001$ \\
\hline \multirow{2}{*}{ Smoking* } & No & $524(72.6)$ & 559 (73.6) & \multirow{2}{*}{0.217} & \multirow{2}{*}{0.641} \\
\hline & Yes & 198 (27.4) & $200(26.4)$ & & \\
\hline \multirow{2}{*}{ Drinking* } & No & $579(83.4)$ & $672(88.5)$ & \multirow{2}{*}{8.157} & \multirow{2}{*}{0.004} \\
\hline & Yes & 119 (16.6) & 87 (11.5) & & \\
\hline
\end{tabular}

* n (\%), Chi-square test.

\# Median (25th and 75th quartile), Mann-Whitney Wilcoxon test.

FBG: fasting blood glucose.

BMI: body mass index.

WC: waist circumference. 
Table 2

Associations of glucose metabolizing gene genotypes with risk of T2DM

\begin{tabular}{|c|c|c|c|c|c|}
\hline Genotype & Case/Control & Unadjusted OR (95\% CI) & $P$ & Adjusted OR $(95 \% \mathrm{CI})^{*}$ & $P^{*}$ \\
\hline \multicolumn{6}{|l|}{ MTNR1B- C/G } \\
\hline \multicolumn{6}{|l|}{ rs10830963 } \\
\hline $\mathrm{CC}$ & $243 / 280$ & 1.0 & - & 1.0 & - \\
\hline $\mathrm{CG}$ & $345 / 350$ & $1.142(0.910-1.433)$ & 0.2512 & $1.026(0.766-1.375)$ & 0.8622 \\
\hline GG & $134 / 129$ & $1.197(0.890-1.610)$ & 0.2353 & $1.044(0.717-1.519)$ & 0.8235 \\
\hline GG vs. $\mathrm{CG}+\mathrm{CC}$ & $722 / 759$ & $1.109(0.850-1.448)$ & 0.446 & $1.028(0.735-1.439)$ & 0.8708 \\
\hline GG+CG vs. CC & $722 / 759$ & $1.157(0.935-1.432)$ & 0.1807 & $1.031(0.784-1.356)$ & 0.8264 \\
\hline \multicolumn{6}{|l|}{ KCNQ1- A/C } \\
\hline \multicolumn{6}{|l|}{ rs151290 } \\
\hline $\mathrm{AA}$ & $71 / 107$ & 1.0 & - & 1.0 & - \\
\hline $\mathrm{AC}$ & $358 / 365$ & $1.482(1.062-2.069)$ & 0.0208 & $1.545(1.002-2.383)$ & 0.0489 \\
\hline $\mathrm{CC}$ & $293 / 287$ & $1.544(1.097-2.172)$ & 0.0126 & $1.603(1.026-2.506)$ & $\mathbf{0 . 0 3 8 3}$ \\
\hline $\mathrm{CC}$ vs. $\mathrm{AC}+\mathrm{AA}$ & $722 / 759$ & $1.125(0.913-1.386)$ & 0.2699 & $1.123(0.858-1.469)$ & 0.3992 \\
\hline $\mathrm{CC}+\mathrm{AC}$ vs. $\mathrm{AA}$ & $722 / 759$ & $1.509(1.097-2.077)$ & 0.0114 & $1.570(1.035-2.381)$ & 0.0339 \\
\hline \multicolumn{6}{|l|}{ KLF14-G/A } \\
\hline \multicolumn{6}{|l|}{ rs972283 } \\
\hline GG & $379 / 389$ & 1.0 & - & 1.0 & - \\
\hline $\mathrm{AG}$ & $286 / 298$ & $0.988(0.797-1.226)$ & 0.9152 & $0.915(0.695-1.204)$ & 0.526 \\
\hline $\mathrm{AA}$ & $57 / 72$ & $0.810(0.555-1.181)$ & 0.273 & $0.763(0.465-1.253)$ & 0.2857 \\
\hline AA vs. GG+AG & $722 / 759$ & $0.814(0.564-1.173)$ & 0.2696 & $0.793(0.490-1.283)$ & 0.3451 \\
\hline $\mathrm{AA}+\mathrm{AG}$ vs.GG & $722 / 759$ & $0.954(0.778-1.170)$ & 0.6503 & $0.887(0.683-1.152)$ & 0.3693 \\
\hline \multicolumn{6}{|l|}{ GCKR-G/A } \\
\hline \multicolumn{6}{|l|}{ rs780094 } \\
\hline $\mathrm{CC}$ & $194 / 186$ & 1.0 & - & 1.0 & - \\
\hline CT & $343 / 348$ & $0.945(0.736-1.214)$ & 0.6578 & $1.077(0.780-1.487)$ & 0.6506 \\
\hline $\mathrm{TT}$ & $185 / 225$ & $0.788(0.596-1.043)$ & 0.0957 & $0.792(0.551-1.137)$ & 0.2061 \\
\hline $\mathrm{TT}$ vs. $\mathrm{CT}+\mathrm{CC}$ & $722 / 759$ & $0.818(0.651-1.027)$ & 0.0841 & $0.754(0.562-1.011)$ & 0.0592 \\
\hline $\mathrm{TT}+\mathrm{CT}$ vs. $\mathrm{CC}$ & $722 / 759$ & $0.883(0.700-1.116)$ & 0.2978 & $0.963(0.712-1.302)$ & 0.805 \\
\hline
\end{tabular}


Adjusted for sex, age, anthropometric measurements, biochemical indexes, smoking and alcohol consumption. 
Table 3

Risk of T2DM associated with genotypes by smoking status and drinking status

\begin{tabular}{|c|c|c|c|c|c|c|c|c|}
\hline Polymorphism & $\begin{array}{l}\text { Non-smoking } \\
\mathrm{OR}^{\mathrm{a}}(95 \% \mathrm{CI})\end{array}$ & $P$ & $\begin{array}{c}\text { Smoking } \\
\text { OR }^{\mathrm{a}}(95 \% \mathrm{CI})\end{array}$ & $P$ & $\begin{array}{l}\text { Non-drinking } \\
\text { OR }^{\mathrm{a}}(95 \% \mathrm{CI})\end{array}$ & $P$ & $\begin{array}{c}\text { Drinking } \\
\mathrm{OR}^{\mathrm{a}}(95 \% \mathrm{CI})\end{array}$ & $P$ \\
\hline \multicolumn{9}{|l|}{ SNP1-MTNR1B } \\
\hline \multicolumn{9}{|l|}{ rs10830963 } \\
\hline $\mathrm{CC}$ & 1.0 & & 1.0 & & 1.0 & & 1.0 & \\
\hline CG & $0.908(0.643-1.282)$ & 0.5836 & $1.366(0.756-2.468)$ & 0.3015 & $1.124(0.823-1.536)$ & 0.4606 & $0.638(0.265-1.541)$ & 0.3181 \\
\hline GG & $1.154(0.745-1.787)$ & 0.5217 & $0.781(0.363-1.679)$ & 0.5262 & $1.207(0.814-1.789)$ & 0.3500 & $0.319(0.087-1.169)$ & 0.0846 \\
\hline $\mathrm{CG}+\mathrm{GG}$ & $0.973(0.704-1.344)$ & 0.8682 & $1.161(0.670-2.013)$ & 0.5950 & $1.148(0.857-1.537)$ & 0.3543 & $0.548(0.237-1.265)$ & 0.1588 \\
\hline \multicolumn{9}{|l|}{ SNP2-KCNQ1 } \\
\hline \multicolumn{9}{|l|}{ rs151290 } \\
\hline $\mathrm{AA}$ & 1.0 & & 1.0 & & 1.0 & & 1.0 & \\
\hline $\mathrm{AC}$ & $1.522(0.928-2.497)$ & 0.096 & $1.972(0.729-5.333)$ & 0.181 & $1.291(0.823-2.025)$ & 0.266 & $5.518(1.116-27.293)^{*}$ & 0.036 \\
\hline $\mathrm{CC}$ & $1.297(0.777-2.165)$ & 0.321 & $3.668(1.318-10.208)^{*}$ & 0.013 & $1.266(0.795-2.015)$ & 0.321 & 8.691 (1.698-44.497)* & 0.0095 \\
\hline $\mathrm{AC}+\mathrm{CC}$ & $1.423(0.885-2.288)$ & 0.145 & $2.566(0.984-6.693)$ & 0.054 & $1.280(0.831-1.972)$ & 0.263 & $6.764(1.430-31.982)^{*}$ & 0.016 \\
\hline \multicolumn{9}{|l|}{ SNP3-KLF14 } \\
\hline \multicolumn{9}{|l|}{ rs972283 } \\
\hline $\mathrm{AA}$ & 1.0 & & 1.0 & & 1.0 & & 1.0 & \\
\hline $\mathrm{AG}$ & $1.446(0.783-2.671)$ & 0.2382 & $0.879(0.327-2.362)$ & 0.7978 & $1.182(0.689-2.027)$ & 0.5445 & $4.267(0.953-19.103)$ & 0.0578 \\
\hline GG & $1.641(0.899-2.997)$ & 0.1069 & $0.737(0.281-1.935)$ & 0.5359 & $1.332(0.786-2.256)$ & 0.2865 & $3.055(0.707-13.199)$ & 0.1348 \\
\hline $\mathrm{AG}+\mathrm{GG}$ & $1.554(0.865-2.790)$ & 0.1403 & $0.794(0.312-2.023)$ & 0.6292 & $1.266(0.759-2.113)$ & 0.3665 & $3.551(0.859-14.687)$ & 0.0802 \\
\hline
\end{tabular}




\section{Applied Physiology, Nutrition, and Metabolism}

\begin{tabular}{|c|c|c|c|c|c|c|c|c|}
\hline \multicolumn{9}{|c|}{ SNP4-GCKR } \\
\hline \multicolumn{9}{|c|}{ rs780094 } \\
\hline $\mathrm{CC}$ & 1.0 & & 1.0 & & 1.0 & & 1.0 & \\
\hline $\mathrm{CT}$ & $1.033(0.708-1.510)$ & 0.865 & $1.257(0.653-2.420)$ & 0.494 & $1.028(0.729-1.449)$ & 0.875 & $1.001(0.385-2.604)$ & 0.998 \\
\hline TT & $0.864(0.569-1.313)$ & 0.495 & $0.745(0.343-1.617)$ & 0.456 & $0.789(0.538-1.158)$ & 0.226 & $0.562(0.183-1.725)$ & 0.314 \\
\hline $\mathrm{CT}+\mathrm{TT}$ & $0.965(0.678-1.373)$ & 0.843 & $1.070(0.575-1.991)$ & 0.831 & $0.932(0.676-1.285)$ & 0.668 & $0.824(0.337-2.014)$ & 0.672 \\
\hline
\end{tabular}

*Adjusted for sex, age, anthropometric measurements, biochemical indexes. 


\section{Figure 1}

Risk of developing T2DM in drinkers and nondrinkers conferred by having different genotypes of KCNQ1 (rs151290). Compared with nondrinkers who carried the AA genotype, the ORs for having T2DM in drinkers with the AC and CC genotypes were $12.072(95 \% \mathrm{CI}=2.843-51.255)$ and $8.147(95 \% \mathrm{CI}=1.868-35.524)$, respectively. All ORs were adjusted for age, sex, BMI, plasma glucose and lipid profile. 


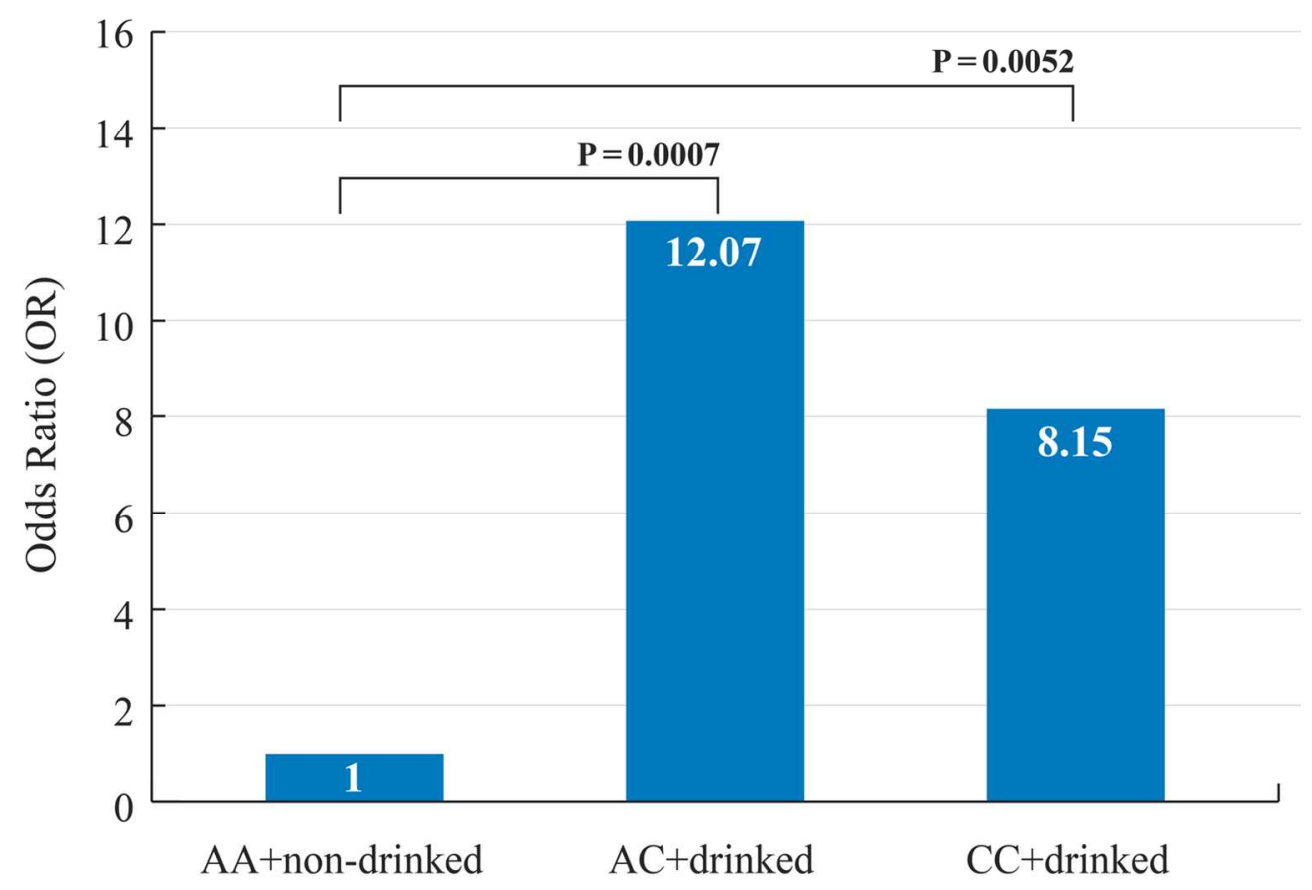

Figure 1 Risk of developing T2DM in drinkers and nondrinkers conferred by having different genotypes of KCNQ1 (rs151290). Compared with nondrinkers who carried the AA genotype, the ORs for having T2DM in drinkers with the AC and CC genotypes were 12.072 (95\%CI $=2.843-51.255)$ and $8.147(95 \% \mathrm{CI}=1.868-$ 35.524), respectively. All ORs were adjusted for age, sex, BMI, plasma glucose and lipid profile.

$129 \times 88 \mathrm{~mm}(300 \times 300$ DPI $)$ 